\title{
O ESCRAVO DA NAÇÃO FLORÊNCIO CALABAR: DA FÁBRICA DE PÓLVORA DA ESTRELA PARA A FÁBRICA DE FERRO SÃO JOÃO DE IPANEMA ${ }^{1}$
}

ROCHA, Ilana Peliciari ${ }^{2}$

RESUMO: O objetivo deste artigo é problematizar a história do escravo da nação Florencio Calabar, no período de 1834-1840. Foram analisados documentos manuscritos da Fábrica de Ferro São João de Ipanema, estabelecimento que o recebeu. Sua história propicia refletir o cotidiano de vários escravos da nação: a transferência, o trabalho e as fugas.

Palavras-chave: Escravidão. Escravos da nação. Fábrica de Ferro São João de Ipanema.

SUMMARY: the purpose of this article is to discuss the history of slave nation Florencio Calabar, in 1834-1840 period. We analyzed documents manuscripts of the iron works in Ipanema, establishment that received it. Her story provides multiple slaves daily reflect the nation: the transfer, the work and the leaks.

Keywords: Slavery. Slaves of the nation. Iron factory São João de Ipanema.

\section{INTRODUÇÃO}

Florencio Calabar foi um dos vários escravos da nação existentes no período colonial e imperial espalhados pelos estabelecimentos públicos - em fábricas, como a Fábrica de Ferro de São João do Ipanema, em Sorocaba e a Fábrica de Pólvora da Estrela, no Rio de Janeiro; em fazendas nacionais, como as Fazendas Nacionais do Piauí e de Santa Cruz, no Rio de Janeiro; para a Corte, no Arsenal da Marinha, na Quinta da Boa Vista; nas Colônias Militares das fronteiras; e nas obras públicas em geral. Com o confisco dos bens dos jesuítas pela Coroa portuguesa em 1760, os escravos pertencentes à ordem passaram a ser incorporados ao patrimônio real. Continuaram presentes até quando também foram atingidos pelas leis graduais de liberdade da década de 1870. Pretende-se aqui observar a biografia de Florêncio Calabar projetada à situação e condições dos escravos da nação.

Para esta análise foram examinados documentos manuscritos da Fábrica de Ipanema e a historiografia da escravidão e dos estabelecimentos públicos. Alinnie Silvestre Moreira analisou os africanos livres e as relações de trabalho na Fábrica de Pólvora de Estrela, no Rio de Janeiro. Apesar de não tratar especificamente dos escravos da nação, a dissertação oferece informações importantes sobre o cenário e as relações de trabalho estabelecidas na fábrica. Com relação à Fábrica de Ferro de Ipanema, o estudo de Mario Danieli Neto analisou os escravos públicos e africanos livres no estabelecimento, no período de 1765-1895, focando principalmente na questão da incompatibilidade do escravo no trabalho industrial. Também o artigo de Afonso Bandeira Florence trata dos escravos na Fábrica, observando a resistência escrava, de 1828 a 1842. Jaime Rodrigues e Mariana Alice P. S. Ribeiro estudou o cotidiano dos africanos livres na fábrica. A tese que estuda os escravos da nação, 1760-1876, destacou a presença

\footnotetext{
${ }^{1}$ Artigo resultado de documentos analisados em Doutorado financiado pela FAPESP.

${ }^{2}$ UFTM - Universidade do Triângulo Mineiro
} 
desses escravos na fábrica de ferro ${ }^{3}$. Com base nesses estudos e na documentação procura-se trazer a história de Florêncio como um fio condutor para compreender a presença dos escravos da nação.

Partimos da vida de Florencio Calabar da Fábrica de Pólvora da Estrela, no Rio de Janeiro. A vinda da família real alterou as condições sociopolíticas da América Portuguesa. Uma das necessidades foi a necessidade de incremento das Academias Militares, por isso uma das medidas foi a criação de estabelecimentos para fortalecerem e oferecerem recursos militares. Entre esses estabelecimentos está a Fábrica de Pólvora da Estrela.

A Fábrica de Pólvora da Estrela foi fundada por D. João VI:

foi criada por decretos no ano de 1808 para produzir pólvora destinada ao consumo do Reino e seus domínios ultramarinos. (...) Em 1813, o Conde de Linhares, Ministro da Guerra, executou o decreto real de fundação da fábrica instalando-a nas proximidades da Lagoa de Rodrigo de Feitas, na Corte. No final da década de 1820, ela foi transferida para a Serra da Estrala, onde hoje ficam os municípios de Magé, Petrópolis e Duque de Caxias, no Estado do Rio de Janeiro ${ }^{4}$.

Uma relação de 26 de julho de 1834 nos fornece essa informação dessa procedência do escravo ${ }^{5}$. Não sabemos se nasceu ali, se veio de outro estabelecimento público ou se foi adquirido por meio de compra. Pois, assim poderia ser a procedência dos escravos da nação: frutos da própria escravaria pública, que pareciam mais frequentes; ou compras posteriores, que ocorreram, mas em menor escala. Em balanço geral da Fábrica de Pólvora de 1824, encontrou-se a despesa paga a Miguel Ferreira Gomes e a Joaquim Ferreira dos Santos por compra de 24 escravos novos para a fábrica ${ }^{6}$.

Mas, também o escravo Florêncio pode ter vindo de outro estabelecimento público, como a Fazenda de Santa Cruz. Essa fazenda pertenceu à Companhia de Jesus, de 1590 até 1759, quando ocorreu a expulsão e o confisco de seus bens. Após a expulsão a Fazenda passou às mãos da Coroa, tornando-se Fazenda Real. Com a vinda da Família Real, em 1808, essa se torna um local de veraneio e, posteriormente, com as mudanças políticas, passa-se a Fazenda Imperial, tornou-se um estabelecimento fornecedor de escravos para vários estabelecimentos ${ }^{7}$. Assim como as Fazendas do Piauí que pertenceram aos inacianos de 1711 até o confisco, passando a pertencer à Coroa ${ }^{8}$.

Assim, em 1834 o escravo Florêncio foi transferido para a Fábrica de Ipanema. A transferência era um acontecimento que ocorria frequentemente no contexto dos escravos da nação. Apesar da dispersão

\footnotetext{
${ }^{3}$ Para a Fábrica de Pólvora ver: MOREIRA, Alinnie Silvestre. Liberdade tutelada. Os africanos livres e as relações de trabalho na Fábrica de Pólvora da Estrela, Serra da Estrela/RJ (c. 1831 - c. 1870). 2005. 256f. Dissertação (Mestrado em História Social) - Instituto de Filosofia e Ciências Humanas, UNICAMP (Universidade Estadual de Campinas). Campinas, p. 106, 2005. Para a Fábrica de ferro São João de Ipanema: NETO, M. D. Escravidão e Indústria: um estudo sobre a Fábrica de Ferro São João de Ipanema - Sorocaba (SP ) - 1765-1895. 2006. 194f. Tese (Doutorado em Economia Aplicada) - Instituto de Economia, UNICAMP (Universidade Estadual de Campinas). Campinas, 15/12/2006. FLORENCE, Afonso Bandeira. Resistência Escrava em São Paulo: A luta dos escravos da fábrica de ferro São João de Ipanema, 1828-1842. Afro-Ásia, 18, pp. 16-17, 1996.

${ }_{5}^{4}$ MOREIRA, A. S. p. 27.

5 Arquivo do Estado de São Paulo, CO5213, Relação Escravos da Nação vindos para a Fábrica de São João de Ipanema, 26 de julho de 1834.

${ }^{6}$ Arquivo Nacional, Fundo IG 7-02 - Junta da Fazenda dos Arsenais (1823 a 1825), Balanço Explicado da Receita, Despesa do Cofre do Producto da venda de Pólvora, 1824.

${ }^{7}$ Ver: ENGEMANN, C. Os Servos de Santo Inácio a Serviço do Imperador: Demografia e Relações Sociais entre a Escravaria da Real Fazenda de Santa Cruz, RJ (1790-1820). 2002. 149f. Dissertação (Mestrado em História Social) Universidade Federal do Rio de Janeiro. Rio de Janeiro, 2002.

${ }^{8}$ LIMA, Solimar Oliveira. Braço Forte. Trabalho escravo nas fazendas da nação no Piauí (1822-1871). Passo Fundo: UFP, p. 32, 2005.
}

Nucleus,v.15,n.2,out.2018 
territorial dos estabelecimentos públicos, houve a conexão ente eles, através das transferências e das trocas de escravos. Os deslocamentos ocorreram em função de várias motivações, os interesses econômicos dos

estabelecimentos, a sazonalidade da produção, a formação de novos estabelecimentos, controle de fronteiras, construção de obras públicas, medidas de disciplina ou de interesse ou pressão dos escravos. O movimento das transferências e trocas formava uma rede que ligava diversos estabelecimentos ${ }^{9}$.

Junto à relação de escravos que constava o nome do escravo Florencio estavam mais 73 escravos, mas que vieram da Fazenda de Santa Cruz. Florencio consta com 40 anos e diferente de boa parte dessa relação, veio solteiro e sem a companhia de sua família. É difícil afirmar a motivação para a vinda de Florencio Calabar, mas como veio sozinho e pelo desenrolar da sua história na Fábrica de Ipanema, podese cogitar que a questão disciplinar influenciou. Além disso, influenciaram também as necessidades de mão de obra do estabelecimento, que eram constantes.

A história de Florêncio prosseguiu na Fábrica de Ferro São João do Ipanema, novos laços e relações foram estabelecidos dentro da nova dinâmica. Carregou suas experiências anteriores somadas às dos que ali já viviam.

A Fábrica de Ferro São João de Ipanema, em Sorocaba (SP), resultou de experiências de fabricação de ferro no morro de Araiçoiaba, por volta do século XVI, com Afonso Sardinha. Posteriormente, a propriedade foi transferida e continuou a produção, mesmo que reduzida. Em 1765, Morgado de Mateus, governador da capitania de São Paulo, enviou a primeira amostra de ferro forjado, originando assim a fábrica. No entanto, sua fundação se deu em 1811, sob uma sociedade de ações, parte de particulares e outra parte da Coroa. Logo, após a ineficiência do sistema de sociedade mista, a Coroa comprou a outra parte, tornando-se sua proprietária total ${ }^{10}$.

A transferência para a Fábrica de ferro não representou uma ruptura total com o tipo de atividade desempenhada, pois, os dois estabelecimentos eram fabris voltados ao fornecimento militar e baseados no "sistema ruro-fabril", ou seja, conjugava atividades agrícolas, ligadas à subsistência, e as atividades fabris.

\section{O TRABALHO}

Não sabemos de fato qual tipo de atividade Florêncio desempenhava, mas o ambiente de trabalho das duas fábricas tinham semelhanças. Tanto na fábrica de pólvora quanto na de ferro, desempenhava suas funções com os outros escravos da nação, que dividiam as atividades com outros trabalhadores com regimes de trabalho variados: africanos livres, escravos jornaleiros, operários livres assalariados, índios, presos etc ${ }^{11}$.

Mariana Alice Pereira S. Ribeiro observa a convivência entre escravos da nação e africanos livres:

a convivência de ambos os grupos não resultou em conflitos pelo contrário: tutelados e escravizados compartilharam suas trajetórias de vida, através das relações de

\footnotetext{
${ }^{9}$ ROCHA, I. P. "Escravos da nação": o público e o privado na escravidão brasileira, 1760-1876. São Paulo: FFLCH-USP, 2012 (Doutorado).

${ }^{10}$ NETO, M. D.. Escravidão e Indústria: um estudo sobre a Fábrica de Ferro São João de Ipanema - Sorocaba (SP ) - 1765-1895. 2006. 194f. Tese (Doutorado em Economia Aplicada) - Instituto de Economia, UNICAMP (Universidade Estadual de Campinas). Campinas, 15/12/2006. FLORENCE, Afonso Bandeira. Resistência Escrava em São Paulo: A luta dos escravos da fábrica de ferro São João de Ipanema, 1828-1842. Afro-Ásia, 18, pp. 16-17, 1996. RIBEIRO, Mariana Alice Pereira Schatzer. Entre a Fábrica e a Senzala: um estudo sobre o cotidiano dos africanos livres na Real Fábrica de Ferro São João do Ipanema - Sorocaba - SP (1840-1870), Assis: UNESP, 2014 (Dissertação de Mestrado). RODRIGUES, Jaime. Ferro, trabalho e conflito: os africanos livres na Fábrica de Ipanema. História Social. Campinas, n. 4-5, pp. 29-44, 1997/1998.

${ }^{11}$ MOREIRA, A. S. p. 28
}

Nucleus,v.15,n.2,out.2018 
solidariedade, alguns formaram famílias entre si, (majoritariamente africanos com escravas, ou até mesmo fugiam juntos) ${ }^{12}$.

Tabela 1 - Número de escravos da nação, da Fábrica de Ferro São João de Ipanema, segundo setores profissionais, em anos entre 1821 e 1854

\begin{tabular}{ccccccccc}
\hline Setores & $\mathbf{1 8 2 1}$ & $\mathbf{\%}$ & $\mathbf{1 8 3 8}$ & $\mathbf{\%}$ & $\mathbf{1 8 4 1}$ & $\mathbf{\%}$ & $\mathbf{1 8 5 4}$ & $\mathbf{\%}$ \\
\hline Atividades industriais e & 25 & 35,2 & 34 & 34,7 & 36 & 36,7 & 28 & 29,8 \\
artesanais & & & & & & & & \\
Transportes & - & - & 8 & 8,2 & 6 & 6,1 & - & - \\
Agricultura & - & - & - & - & 1 & 1,0 & - & - \\
Serviços especializados & - & - & 1 & 1,0 & 8 & 8,2 & - & - \\
Serviços não especializados & 5 & 7,0 & 27 & 27,5 & 47 & 48,0 & 46 & 48,4 \\
s.i. & 41 & 57,7 & 28 & 28,6 & - & - & 21 & 22,1 \\
Total & 71 & 100,0 & 98 & 100,0 & 98 & 100,0 & 95 & 100,0 \\
\hline
\end{tabular}

Fonte: Rocha, 2012

Obs.: Como atividades industriais incluem-se as seguintes funções: carpinteiro, aprendizes, torneiro, pedreiro, oleiro, ferreiro, carvoeiros, cavoqueiros, broqueador, moldador, refinador, mineiro, mestres (ferreiro, carpinteiro, moldador, fundidor e da carvoaria). Em atividades de transportes estão os escravos arrieiros, carreiros e tropeiros. Na agricultura, incluem-se os campeiros, capineiros e carroceiros. Em escravos prestando serviço especializado incluemse: os enfermeiros, os cozinheiros e as costureiras. Nos serviços não especializados estão os ajudantes dos fornos, os escravos nos pilões e no corte da madeira, os tiradores de carvão, feitores e os serventes. E no setor sem informação estão os escravos sobre os quais não constava informação de ofício, nesse caso muitas mulheres. No total de cada ano foram excluídos os menores e 1854, também os escravos inválidos. Em 1854, serviços sem especialização incluem serviços na mineração, carvoarias, roças e tropa, sendo que 44 correspondem a mulheres. Alguns escravos apresentaram mais de uma especialização; optou-se, na elaboração da tabela, por indicar apenas uma. S.i. significa sem informação.

A ocupação de Florêncio Calabar não foi identificada na documentação pesquisada. Na Fábrica de Ipanema, pode-se observar uma diversidade de atividades profissionais que esse escravo dedicava-se, conforme a tabela 1. A relação que consta a entrada de Florêncio na Fábrica de Ipanema apresenta outros escravos que vieram da Fazenda de Santa Cruz. Com relação a esses escravos foram identificados os seguintes ofícios indicados para os homens: 3 carpinteiros, 2 falquejadores, 11 ferreiros, 5 pedreiros, 2 cabouqueiros, 4 oleiros, 2 corrieiros, 1 barbeiro e 2 lavradores ${ }^{13}$.

\section{A - AS FUGAS}

Calabar chegou em 1834 e carregou da Fábrica de Pólvora para a Fábrica de Ipanema sua história, que nos é apresentada nas entrelinhas dos documentos: "como he escravo muito perigoso pelos assassínios que fez na Fabrica de Polvora no Rio, será bem de se recomendar a Policia a sua captura"14.

Logo em 1835 seu nome é citado como participante de uma conspiração:

Em 1835 foi descoberta uma conspiração daqueles escravos e João Bloem, então administrador da fábrica, enviou ao presidente da província uma 'Relação dos escravos cabeças de desordem projetada neste estabelecimento'. Nesta relação ele fazia uma descrição dos escravos fugiram, assim como dos objetos que tinham sido levados na fuga, aproveitando para alertar que os fugitivos sempre 'andam juntos'. Os escravos tinham projetado o 'rompimento de desordens' mas de uma maneira infelizmente não temos conhecimento, foram descobertos e às duas horas da tarde do dia 21 de abril

\footnotetext{
${ }^{12}$ MARIANA, p. 167.

13 Arquivo do Estado de São Paulo, CO5213, Relação Escravos da Nação vindos para a Fábrica de São João de Ipanema, 26 de julho de 1834.

${ }^{14}$ Arquivo do Estado de São Paulo, CO5214, Ofício de africano livre devolvido e de escravo fugido, 12 de dezembro de 1839.
} 
tiveram seu plano desbaratado. Cinco dos 'cabeças' conseguiram fugir, tendo sido preso apenas Florêncio Calabar, um ‘incorrigível [...] valentão’ (FLORENCE, 1996, p. 23)

Assim, vir de outro estabelecimento não o privou de criar laços e participar de grupos. Observamos que não foi uma fuga isolada, mas que envolveu outros cativos do estabelecimento. A fuga caracteriza-se como uma das principais ações de rebeldia e resistência por parte dos escravos privado e, como nos mostra a história de Florencio, também da escravaria pública. Ressalta-se aqui é a participação de um escravo mais velho, o que não corresponde ao perfil evidenciado nas fugas de escravos de particulares.

É importante notar que em um período anterior, em 1828, o racionamento de alimentação e vestuário provocou a elaboração de um requerimento dos escravos ${ }^{15}$. Demonstra-se que os escravos da Fábrica de Ipanema questionavam sua situação e usavam de diversas ferramentas para modifica-la. A tabela 2 apresenta o número de escravos fugidos da Fábrica de Ipanema. Observa-se, pela tabela, um aumento do número de escravos fugidos no estabelecimento, de 6\%, em 1821 para aproximadamente $8 \%$ e $16 \%$ para os anos de 1838 e 1843.

Os administradores procuraram alternativas para controlar a população cativa. Allinie S. Moreira comparando a Fábrica de Pólvora com a Fábrica de ferro comenta que nos dois estabelecimentos: "localizamos as mesmas disposições das senzalas dos escravos, que ficavam próximas à residência do

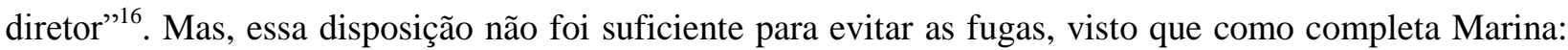
"No Brasil o trancamento das portas das senzalas não foi muito eficaz, visto que são abundantes os casos de escravos que fugiam de suas moradias durante a noite" ${ }^{\prime 17}$.

Tabela 2 - Escravos fugidos da Fábrica de Ferro São João de Ipanema, entre 1821 e 1843

\begin{tabular}{cccccc}
\hline Ano & Masculino & Feminino & $\begin{array}{c}\text { Total de } \\
\text { fugitivos }\end{array}$ & $\begin{array}{c}\text { Total (existentes e } \\
\text { fugitivos) }\end{array}$ & $\begin{array}{c}\% \text { de } \\
\text { fugitivos }\end{array}$ \\
\hline 1821 & 5 & - & 5 & 83 & 6,0 \\
1838 & 10 & 1 & 11 & 134 & 8,2 \\
1843 & 18 & 4 & 24 & 144 & 16,6 \\
\hline
\end{tabular}

Fonte: Rocha, 2012

Obs.: Não se pode afirmar que esses números representem todas as fugas, mas representam uma amostragem. No ano de 1843 também fugiram 4 africanos livres.

Além da disposição das senzalas, as fábricas contavam com feitores com um limite de escrava para vigiar:

\begin{abstract}
vinte e cinco escravos, que vem a ser o número que razoavelmente pode administrar nos serviços, e todos serão obrigados a residir na mesma casa dos escravos, ou, em outra qualquer que lhe fique mais próxima. (...) $\$ 5^{\circ}$. Aos Feitores dos Escravos pertence a correcção imediata dos mesmos por culpas leves, e pelas graves dar parte ao Director depois de ter posto em segurança o Escravo delinquente, havendo receio de fuga, para aquelle determinar o castigo correspondente, entregando-o à Justiça, se for verdadeiro delinquente: o mesmo no castigo das culpas leves deverá seguir as ordens do Director quando dê algumas ${ }^{18}$.
\end{abstract}

\footnotetext{
${ }^{15}$ FLORENCE, Afonso Bandeira. Resistência Escrava em São Paulo: A luta dos escravos da fábrica de ferro São João de Ipanema, 1828-1842. Afro-Ásia, 18, pp. 16-17, 1996

${ }^{16}$ MOREIRA, A. S. p. 59, 2005.

${ }^{17}$ MARINA, p. 61

${ }^{18}$ MORAES. VERGUEIRO, p. 138-139, 1858.
} 
As ações de resistência de Florêncio não ficaram restritas a esse ocorrido, mas como relata documentação de 1839: "Fugio desta a 3 dias o escravo Calabar, muito conhecido nessa cidade, por ter já

estado por 3 vezes na cadeia: elle fugio com corrente no pé direito" ${ }^{19}$. Observa-se que uma punição efetuada foi a prisão.

Assim, representou uma ameaça para o controle da administração da fábrica, seu nome é citado em 1836, como solteiro e nas observações gerais, que vivia preso; e, em 1838, consta como fugido. Não sabemos ao certo o tempo dessas fugas e o tempo que ficou preso, mas a representatividade de suas ações representaram as tentativas de modificar sua situação.

Outros exemplos mostram essas fugas repetidas, como é o caso de Victor, que consta na relação dos fugidos de 1821, "fugiu quatro vezes" 20 e "Manoel Teixeira é incorrigível, vadio e só de fugida paresse-me que já passa de vinte vezes" ${ }^{\prime 2}$.

Florêncio carregava as marcas da escravidão. Foi descrito com: "bastantes cabellos brancos, idade 60 annos mais, ou menos, muito mal encarado de feições, nariz chato, levou vestea e calça de panno azul bastante estragado, huã corrente no pé direito, aonde deve ter o sinal no caso de a ter tirado" ${ }^{22}$.

Em relação dos escravos da fábrica de 1943 não se encontra nenhuma referência à Florêncio. Que caminho tomou? Ficamos aqui com algumas linhas de sua história, mas a certeza de sua luta contra a condição escrava. Remendar essas histórias de vida podem evidenciar a vida dos escravizados.

\section{CONSIDERAÇÕES FINAIS}

Escrever a biografia de um escravo é complicado. Longe de uma biografia, aqui temos pedaços da vida de Florêncio Calabar, um escravo da nação. Foi necessário remendar documentos esparsos que trouxeram insites de sua vida. A partir desse insites foi possível conhecer alguns episódios da vida de escravos da nação.

Florêncio passou por momentos característicos do cotidiano da escravaria pública: a transferência de estabelecimento e as fugas.

\section{REFERÊNCIAS}

ENGEMANN, C. Os Servos de Santo Inácio a Serviço do Imperador: Demografia e Relações Sociais entre a Escravaria da Real Fazenda de Santa Cruz, RJ (1790-1820). 2002. 149f. Dissertação (Mestrado em História Social) - Universidade Federal do Rio de Janeiro. Rio de Janeiro, 2002.

FLORENCE, A.B. Resistência Escrava em São Paulo: A luta dos escravos da fábrica de ferro São João de Ipanema, 1828-1842. Afro-Ásia, 18, pp. 16-17, 1996.

\footnotetext{
${ }^{19}$ Arquivo do Estado de São Paulo, CO5214, Ofício de africano livre devolvido e de escravo fugido, 12 de dezembro de 1839.

${ }^{20}$ Arquivo do Estado de São Paulo, CO5214, folder 04, ofício do diretor da Fábrica de Ferro São João de Ipanema ao Presidente da Província de São Paulo, 20 de abril de 1835.

${ }^{21}$ Arquivo Nacional, IG5-20, Série Guerra - Fábrica de Ipanema, Ofício do Diretor da Fábrica de Ipanema para o Ministro e Secretário d'Estado dos Negocios da Guerra, de 15-04-1840.

${ }^{22}$ Arquivo do Estado de São Paulo, CO5214, folder 04 A, Signaes característicos do escravo fugido Florencio Calabar, 08 de agosto de 1835.
} 
LIMA, S.O. Braço Forte. Trabalho escravo nas fazendas da nação no Piauí (1822-1871). Passo Fundo: UFP, p. 32, 2005.

MOREIRA, A.S. Liberdade tutelada. Os africanos livres e as relações de trabalho na Fábrica de Pólvora da Estrela, Serra da EstrelaRJ (c. 1831 - c. 1870). 2005. 256f. Dissertação (Mestrado em História Social) - Instituto de Filosofia e Ciências Humanas, UNICAMP (Universidade Estadual de Campinas). Campinas, 2005.

NETO, M. D. Escravidão e Indústria: um estudo sobre a Fábrica de Ferro São João de Ipanema Sorocaba (SP ) - 1765-1895. 2006. 194f. Tese (Doutorado em Economia Aplicada) - Instituto de Economia, UNICAMP (Universidade Estadual de Campinas). Campinas, 15/12/2006.

RIBEIRO, M.A.P.S. Entre a Fábrica e a Senzala: um estudo sobre o cotidiano dos africanos livres na Real Fábrica de Ferro São João do Ipanema - Sorocaba - SP (1840-1870), Assis: UNESP, 2014 (Dissertação de Mestrado).

ROCHA, I. P. "Escravos da nação": o público e o privado na escravidão brasileira, 1760-1876. São Paulo: FFLCH-USP, 2012 (Doutorado).

RODRIGUES, J. Ferro, trabalho e conflito: os africanos livres na Fábrica de Ipanema. História Social. Campinas, n. 4-5, pp. 29-44, 1997/1998. 